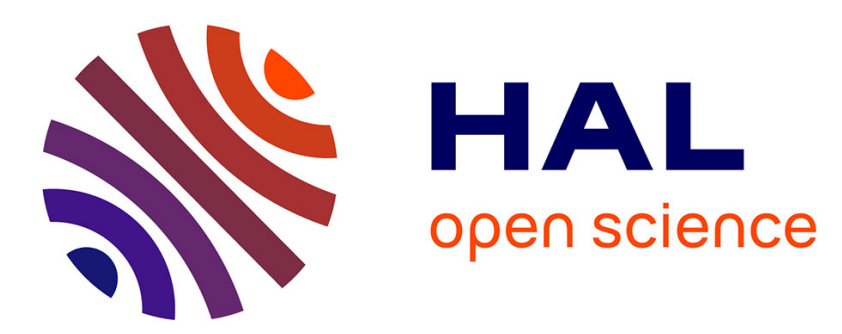

\title{
Eighteen SSR-primers for tetraploid Adansonia digitata and its relatives
}

Anders Søndergaard Larsen, Alexandre Vaillant, Daniel Verhaegen, Erik Dahl Kjær

\section{> To cite this version:}

Anders Søndergaard Larsen, Alexandre Vaillant, Daniel Verhaegen, Erik Dahl Kjær. Eighteen SSRprimers for tetraploid Adansonia digitata and its relatives. Conservation Genetics Resources, 2009, 1, pp.325-328. cirad-00845683

\section{HAL Id: cirad-00845683 http://hal.cirad.fr/cirad-00845683}

Submitted on 17 Jul 2013

HAL is a multi-disciplinary open access archive for the deposit and dissemination of scientific research documents, whether they are published or not. The documents may come from teaching and research institutions in France or abroad, or from public or private research centers.
L'archive ouverte pluridisciplinaire HAL, est destinée au dépôt et à la diffusion de documents scientifiques de niveau recherche, publiés ou non, émanant des établissements d'enseignement et de recherche français ou étrangers, des laboratoires publics ou privés. 


\title{
Eighteen SSR-primers for tetraploid Adansonia digitata and its relatives
}

\author{
Anders Søndergaard Larsen · Alexandre Vaillant • \\ Daniel Verhaegen · Erik Dahl Kjær
}

Received: 4 August 2009/Accepted: 10 August 2009/Published online: 29 August 2009

(C) Springer Science+Business Media B.V. 2009

\begin{abstract}
Co-dominant markers suitable for molecular ecological studies in the genus Adansonia are highly desirable in order to be able to address a number of interesting research questions related to the special life history traits, gene flow, and distribution dynamics of the Adansonia species. This note presents a set of 18 SSRprimers developed for Adansonia digitata, and tested for cross-amplification on all members of the Adansonia genus. All reported primers were found to amply loci with more than two alleles per locus in Adansonia digitata, reflecting its tretraploid nature. Segregation of alleles in open pollinated progenies from trees with four alleles per locus indicated polysomic inheritance for 14 of the 18 loci.
\end{abstract}

Keywords Adansonia digitata B Baobab .

Microsatellites - SSR - Segregation · Crossamplification · Polyploid

\section{Introduction}

The African baobab, Adansonia digitata L., is a spectacular and intriguing tree species due to its autecology, Africanwide distribution and large socio-economic importance.

A. S. Larsen $(\square) \cdot$ E. D. Kjær

Forest \& Landscape Denmark, Copenhagen University, Hørsholm Kongevej 11, 2970 Hørsholm, Denmark

e-mail: ansl@life.ku.dk

A. Vaillant $\cdot$ D. Verhaegen

CIRAD-BIOS, UR 39 «Génétique Forestière», Campus

International de Baillarguet TA A-39/C, 34398

Montpellier Cedex 5, France
From a biological point of view this pachycaul has been denoted the worlds largest succulent with the ability to grow more than 1000 years old (Patrut et al. 2007). Its trunk is capable of absorbing water to an extent so the circumference of the trunk expands several percent. Being leafless except 2 to 3 months a year, it is assumed that considerable photosynthesis is taking place in the bark. Culturally, the tree is subject to many myths and superstitions (Wickens and Lowe 2008).

Adansonia includes seven additional species that share many morphological and biological characteristics with their African relative. They appear, however, to have only half the number of chromosomes (Baum and Oginuma 1994). Six of them are native to Madagascar (A. za Baill., A. madagascariensis Baill., A. rubrostipa Jum.\& H Perrier, A. suarezensis H. Perrier, A. perrieri Capuron, A. grandidieri Baill.) and one to Australia (A. gregorii Mueller).

The large flowers of A. digitata are open for a single night per flower and are predominantly pollinated by fruit bats (Baum 1995a). Little is known about the foraging patterns of Old World fruit bats, and thus the pollination of baobabs (Andriafidison et al. 2005). Gene flow studies will thus serve the dual purpose of providing insight into the dispersal processes that shape the genetic structure of the baobabs as well as providing indirect information on fruit bat foraging behavior. Also, estimates of seed dispersal and differentiation between populations will be very useful for monitoring impacts from anthropogenic influence and for predicting consequences of climatic fluctuations. This is particularly important since several Malagasy species have long been known to be threatened, and the African baobab seems to be declining due to heavy browsing and human activities, especially in East and Central Africa (Baum 1995b; Jama et al. 2008; Wilson 2008). The phylogeography of A. digitata has long intrigued researchers 
with its present disjunct distribution and anthropological indices of late arrival to its western distribution range (Wickens 1982). Use of a combination of marker types might be able to provide an explanation (e.g., Dick and Heuertz 2008).

Polyploid species cause some difficulties for the molecular geneticist. Direct sequencing is more difficult compared to diploids, and scoring of co-dominant markers is challenging. This is especially true where one needs to know dosages and predict segregation as is the case of paternity studies. Segregation provides a challenge, because of the difficulties in unraveling poly, disomic, or mixed inheritance. For polysomically inherited loci, the issue of double reduction further complicates things. When it comes to even simple computations, there is also a lack of software dealing with these omnipresent polyploids, whereas more advanced analyses and algorithms are almost non-existent.

\section{Materials and methods}

Individuals for development and testing of the present SSR library were located in and around the village of Nobéré, Burkina Faso $\left(11^{\circ} 33.900^{\prime} \mathrm{N} 1^{\circ} 12.300^{\prime} \mathrm{W}\right)$. Bark samples for DNA extraction were taken out using a bark blazer, and samples were field dried in silica gel. DNA was extracted using Qiagen DNEasy Plant Mini Kit. A microsatelliteenriched library was built following the protocol of Billotte et al. (1999). Total DNA was digested using Alu I (New England Biolabs). Adaptors Rsa21 and Rsa25 (Edwards et al. 1996) were ligated to the fragments using T4 ligase (Roche). Enrichments were done for the motifs $(\mathrm{TG})_{10}$, $(\mathrm{TC})_{10}$, (TTA $)_{8},(\mathrm{TGA})_{8}$, and (TTC) $)_{8}$ following the protocol of Glenn and Schable (2005) by use of Streptavidin MagneSphere Paramagnetic Particles (Promega). Enriched DNA was PCR amplified and cloned using the pGEM-T Easy Vector System Kit (Promega). Following screening based on the $\beta$-galactosidase gene, 288 plasmids were isolated. A PCR-based test for insert presence and size resulted in 192 plasmids of length between 500 and $1,000 \mathrm{bp}$. These were sequenced in both orientations at Macrogen, Korea using a 3730xl sequencer (ABI).

Primer sequences were designed for 32 loci. From these, 18 were selected based on ability to amplify, level of polymorphism, and interpretability. Testing was carried out on a sample of 214 individuals of A. digitata, and 30 individuals of the seven remaining Adansonia species (Table 2). Tests were carried out in $10 \mu \mathrm{l}$ reactions using Qiagen Multiplex PCR kit following the manufacturer's instructions. For testing, a $T_{\mathrm{A}}$ of $58^{\circ} \mathrm{C}$ was used for all loci.

\section{Results and discussion}

All of the 18 reported loci were found to be highly polymorphic and very simple to score (Table 1). SSRs based on tri-nucleotide repeats were found most easy to score and could be subjected to auto-detection of alleles, whereas di-nucleotide repeats with long bp-ranges need manual scoring due to low signal of the longer alleles.

Looking at 20-25 offspring genotypes from each of 30 mother trees with open pollination (unpublished data), it was possible to infer on the inheritance of the loci. In situations where maternal genotypes included four different alleles, the inheritance could be inferred by looking at progenies with four different alleles of which only two were shared with the maternal genotype. For such motheroffspring arrays, polysomic inheritance could be inferred if any given maternal allele had paired with each of the remaining three in the maternal gametes. If the offspring had less than four different alleles, double reduction could not be ruled out as an explanation for the seemingly random pairing of alleles. However, double reduction would still indicate polysomic inheritance at the given locus. Using the first approach, loci Ad04, Ad06, Ad07, Ad11, Ad14, and Ad14 were inferred to be polysomically inherited. Expanding to look also at offspring that had less than four alleles, polysomic inheritance was inferred for all loci except Ad09, Ad10, Ad12, and Ad13. More thorough testing will be possible once it has been established to what extent the allele peak area can be used to estimate the allelic configuration (e.g., Catalán et al. 2006). It is suggested to test this by analysis of offspring from controlled test crosses between individuals with selected genotypes (e.g., Stift et al. 2008).

High transferability of primers within the genus was observed as is evident from Table 2. Having half as many chromosomes compared to A. digitata, the remainder of Adansonia species were expected to have no more than two alleles per locus. However, some primer pairs were found to give three or four bands when amplifying certain individuals. This was consistent even at higher annealing temperatures. The reason for this is unknown but it could be speculated that it is caused by amplification of loci in multicopy-DNA or genomes from an ancient polyploidization event. As would be expected, some primers did not amplify in all the species. In addition, some primers did not amplify in all individuals in a species. The latter is expected to be due to a poor match between primer and priming site, and might be possible to fix by redesigning the primers. Further work on testing transferability and verification of priming sites is encouraged. 
Table 1 The reported SSR loci listed with GenBank accession numbers and forward and reverse primer sequences

\begin{tabular}{|c|c|c|c|c|c|c|c|c|c|c|}
\hline \multirow[t]{2}{*}{ Locus name } & \multirow{2}{*}{$\begin{array}{l}\text { GenBank } \\
\text { Accession no. }\end{array}$} & \multicolumn{2}{|l|}{ Primer sequences $5^{\prime}-3^{\prime}$} & \multirow[t]{2}{*}{ Motif } & \multirow{2}{*}{$\begin{array}{l}\text { Size range } \\
\text { (bp) }\end{array}$} & \multirow[t]{2}{*}{$\mathrm{N}_{\mathrm{A}}$} & \multicolumn{4}{|c|}{ Peaks per individual (fraction) } \\
\hline & & $\mathrm{F}$ & $\mathrm{R}$ & & & & $p(1)$ & $p(2)$ & $p(3)$ & $p(4)$ \\
\hline Ad01 & GQ303181 & CATTGCCAGGAATGCTTTTGC & GGATTGCCAGGTCTACTAC & $(\mathrm{AG})_{19}$ & $96-125$ & 8 & 0.24 & 0.61 & 0.15 & 0.00 \\
\hline Ad02 & GQ303182 & TGCTGACTAGCAGTTTCCTATG & TCAGATGCCAAACATTCACACC & $(\mathrm{TC})_{15}$ & $267-295$ & 8 & 0.07 & 0.42 & 0.40 & 0.12 \\
\hline Ad03 & GQ303183 & GGATCAAATTATGGTTAAGGC & CCAATTTTGAGCCAATTCTCA & $(\mathrm{GA})_{21}$ & $143-175$ & 9 & 0.05 & 0.47 & 0.40 & 0.08 \\
\hline Ad04 & GQ303184 & GTTGCTTGTGTGCTTACCC & САТСССТСТССССАТТСС & $(\mathrm{CT})_{20}$ & $173-236$ & 27 & 0.19 & 0.46 & 0.26 & 0.10 \\
\hline Ad05 & GQ303185 & CTCAACAAGGTTCGGATGTCGTATG & GTCTGCCGGGTGTTTTGCATG & $(\mathrm{CA})_{12}(\mathrm{CT})_{12}$ & $295-319$ & 10 & 0.12 & 0.50 & 0.32 & 0.06 \\
\hline Ad06 & GQ303186 & TGCATCAGCTTTCACTCCAGAC & GCCACCCATAAAACCCAATCC & $(\mathrm{TC})_{19}$ & $129-154$ & 8 & 0.01 & 0.21 & 0.56 & 0.22 \\
\hline Ad07 & GQ303187 & TAGAAAATTAGCAGATAAGTGC & GATTTCGGTGATATGTTGTAG & $(\mathrm{AG})_{18}$ & $159-193$ & 17 & 0.00 & 0.18 & 0.55 & 0.27 \\
\hline Ad08 & GQ303188 & TCTAAAGCCTGTAAGGAAAAATGGG & TTCTCCGTTCACTCTGTACTTCC & $(\mathrm{GAA})_{14}$ & $267-296$ & 11 & 0.03 & 0.29 & 0.52 & 0.15 \\
\hline Ad09 & GQ303189 & TACCACTTCTCCAGATGCTAC & ACTGGCTAGAGATGCGTTG & $(\mathrm{AAG})_{11}$ & 190-209 & 5 & 0.04 & 0.46 & 0.45 & 0.06 \\
\hline Ad10 & GQ303190 & GCAGCTTGCCTCGTCATATA & CCAATGGCAATGTGTCTGACG & $(\mathrm{CT})_{6} \mathrm{CC}(\mathrm{CT})_{19}$ & $216-262$ & 7 & 0.42 & 0.47 & 0.09 & 0.01 \\
\hline Ad11 & GQ303191 & ATCAGCCATTCTGCATACCTGC & TAGGCACAAAACTGAGATGCACAG & $(\mathrm{CA})_{13}(\mathrm{AT})_{6}$ & $118-181$ & 26 & 0.01 & 0.09 & 0.46 & 0.44 \\
\hline Ad12 & GQ303192 & GCTTGTCAAGCAATTCCCC & ACTTTGTCCCACCTGTTTCTC & $(\mathrm{AG})_{16}$ & $162-175$ & 5 & 0.19 & 0.47 & 0.31 & 0.03 \\
\hline Ad13 & GQ303193 & CCССАCTTCAGATCAAGTAAGTC & GCTGTATTTCTGAGCCTGAGAAG & $(\mathrm{AC})_{14}$ & $305-330$ & 11 & 0.01 & 0.20 & 0.57 & 0.21 \\
\hline Ad14 & GQ303194 & CTTGATTGGAATACGGGAAATGGAG & CCAAACCAATTGGACTTTGACCTTC & $(\mathrm{AC})_{13}$ & $170-191$ & 10 & 0.00 & 0.12 & 0.51 & 0.36 \\
\hline Ad15 & GQ303195 & TGAAGAGACAAAGCAAGAAG & CATGACATCTCCTTGAACC & $(\mathrm{GAA})_{14}$ & $130-161$ & 9 & 0.13 & 0.41 & 0.43 & 0.03 \\
\hline Ad16 & GQ303196 & TGCATCAGCTTTCACTCCAGAC & GCCACCCATAAAACCCAАTCC & $(\mathrm{TA})_{5}(\mathrm{TG})_{19}$ & $219-254$ & 14 & 0.01 & 0.21 & 0.54 & 0.24 \\
\hline Ad17 & GQ303197 & GCGCCTTAGAAAGGACTTGTTAGAG & GCCAACAGCCTTAGTAGTCCAAG & $(\mathrm{AC})_{14}$ & $174-215$ & 22 & 0.01 & 0.21 & 0.51 & 0.27 \\
\hline Ad18 & GQ303198 & ACCGCTTCCGTTCTCATTCC & ACCACCACTACACCGTCATTG & $(\mathrm{TG})_{17}$ & $257-291$ & 18 & 0.14 & 0.40 & 0.37 & 0.09 \\
\hline
\end{tabular}

Size range gives the interval in base pairs for which alleles were found in the studied population. $N_{\mathrm{A}}$ gives the number of alleles found for each locus, and $p(1)-p(4)$ gives the fraction of genotypes with 1, 2, 3 and 4 different alleles, respectively. Diversity was estimated based on 214 genotyped individuals 
Table 2 Results from the transferability test

\begin{tabular}{|c|c|c|c|c|c|c|c|}
\hline \multirow[t]{2}{*}{ Species } & \multicolumn{2}{|c|}{$\begin{array}{l}\text { Section } \\
\text { Brevitubae }\end{array}$} & \multicolumn{5}{|c|}{ Section Longitubae } \\
\hline & A. gran. & A. suar. & A. greg. & A. $z a$ & A. perr. & A. rubr. & A. mada \\
\hline$N$ & 3 & 2 & 11 & 5 & 3 & 2 & 4 \\
\hline Ad01 & + & + & + & $+^{\mathrm{a}}$ & + & + & $+^{\mathrm{a}}$ \\
\hline Ad02 & + & + & + & + & + & + & + \\
\hline Ad03 & $+^{\mathrm{b}}$ & - & + & $+^{\mathrm{a}, \mathrm{b}}$ & $+^{\mathrm{b}}$ & + & $+^{\mathrm{b}}$ \\
\hline Ad04 & + & $+^{\mathrm{b}}$ & $+^{\mathrm{a}}$ & + & $+^{\mathrm{b}}$ & - & $+^{\mathrm{b}}$ \\
\hline Ad05 & + & + & $+^{\mathrm{b}}$ & + & $+^{\mathrm{a}}$ & + & + \\
\hline Ad06 & + & + & + & $+^{\mathrm{a}}$ & + & + & $+^{\mathrm{a}}$ \\
\hline Ad07 & + & + & - & + & $+^{\mathrm{b}}$ & + & + \\
\hline Ad08 & + & + & + & + & + & + & + \\
\hline Ad09 & + & + & + & + & + & + & + \\
\hline Ad10 & + & + & + & $+^{\mathrm{b}}$ & - & + & $+^{\mathrm{b}}$ \\
\hline Ad11 & $+^{\mathrm{a}}$ & + & $+^{\mathrm{a}}$ & + & $+^{\mathrm{a}}$ & + & $+^{\mathrm{a}}$ \\
\hline Ad12 & - & - & + & $t^{\mathrm{b}}$ & $+^{\mathrm{b}}$ & - & - \\
\hline Ad13 & + & + & + & + & $+^{\mathrm{b}}$ & + & + \\
\hline Ad14 & + & + & + & + & + & + & + \\
\hline Ad15 & + & + & + & + & $+^{\mathrm{a}}$ & + & + \\
\hline Ad16 & + & + & + & + & $+^{\mathrm{a}}$ & - & + \\
\hline Ad17 & + & + & $+^{\mathrm{b}}$ & $+^{\mathrm{b}}$ & $+^{\mathrm{b}}$ & + & $+^{\mathrm{b}}$ \\
\hline Ad18 & + & + & + & + & $+^{\mathrm{b}}$ & + & + \\
\hline
\end{tabular}

Amplification (+) and no amplification ( - ) is given for each combination of locus and species. $N$ gives the number of individuals tested, superscript letter (a) denotes that one or more individuals had more than two bands for the given locus and superscript letter (b) denotes that one or more individuals did not amplify

Acknowledgments Thanks to David Baum and Jack D. Pettigrew for providing samples for testing crossamplification.

\section{References}

Andriafidison D, Andrianaivoarivelo RA, Ramilijaona OR, Razanahoera MR, MacKinnon J, Jenkins RKB, Racey PA (2005) Nectarivory by endemic malagasy fruit bats during the dry season. Biotropica 38:85-90
Baum DA (1995a) The comparative pollination and floral biology of baobabs (Adansonia-Bombacaceae). Ann Miss Bot Gard 82: 322-348

Baum DA (1995b) A systematic revision of Adansonia (Bombacaceae). Ann Miss Bot Gard 82:440-471

Baum DA, Oginuma K (1994) A review of chromosome numbers in Bombacaceae with new counts for Adansonia. Taxon 43: $11-20$

Billotte N, Lagoda PJL, Risterucci A-M, Baurens F-C (1999) Microsatellite enriched libraries: applied methodology for the development of SSR markers in tropical crops. Fruits 54:277-288

Catalán P, Segarra-Moragues JG, Palop-Esteban M, Moreno C, Gonzales-Candelas F (2006) A Bayesian approach for discriminating among alternative inheritance hypotheses in plant polyploids: the tetraploid origin of genus Borderea (Dioscoreaceae). Genetics 172:1939-1953

Dick CW, Heuertz M (2008) The complex biogeographic history of a widespread tropical tree species. Evolution 62:2760-2774

Edwards KJ, Barker JH, Daly A, Jones C, Karp A (1996) Microsatellite libraries enriched for several microsatellite sequences in plants. Biotechniques 20:758-760

Glenn TC, Schable NA (2005) Isolating microsatellite DNA loci. Methods Enzymol 395:202-222

Jama BA, Mohamed AM, Mulatya J, Njui AN (2008) Comparing the "Big Five": a framework for the sustainable management of indigenous fruit trees in the drylands of East and Central Africa. Ecol Indic 8:170-179

Patrut A, Reden KF, Pohlman JW, Wittmann R, Mitchell CS, Lowy DA, Alberts AH, Gerlach D, Xu L (2007) Radiocarbon dating of a very large African baobab. Tree Physiol 27:1569-1574

Stift M, Berenos C, Kuperus P, Tienderen PH (2008) Segregation models for disomic, tetrasomic and intermediate inheritance in tetraploids: a general procedure applied to Rorippa (Yellow Cress) microsatellite data. Genetics 179:2113-2123

Wickens GE (1982) The baobab-Africa's upside-down tree. Kew Bull 37:173-209

Wickens GE, Lowe P (2008) The baobabs: Pachycauls of Africa. Madagascar and Australia, Springer

Wilson RT (2008) Vital statistics of the baobab (Adansonia digitata). Afr J Ecol 26:197-206 